\section{Fracture Toughness of Wet and Dry Particulate Materials Comprised of Colloidal Sized Particles: Role of Plastic Deformation}

\author{
Mitchell L. Sesso and George V. Franks
}

Chemical Engineering, The University of Melbourne

This work demonstrates a method of measuring the fracture toughness of particulate materials comprised of colloidal sized particles over a wide range of saturation. Diametral compression of cylinders containing flaws of controlled length was used to measure the mode I fracture toughness. The effect of degree of saturation on the fracture toughness of slip cast ceramic grade alumina ( $\mathrm{d} 50=0.7 \mu \mathrm{m})$ was investigated. Dry powder compacts have significantly lower fracture toughness than when the powder compact is nearly fully saturated. All observations are consistent with the fracture mechanism being predominantly brittle for the dry samples but predominantly ductile in the nearly saturated samples. The additional dissipation that occurs during the ductile fracture of the nearly saturated samples is due to plastic deformation in front of the crack tip. This well-known mechanism for toughening in metals has been quantified for the first time in soft matter. Analysis of the results indicates that the size of the plastic dissipation zone is more than an order of magnitude larger in the nearly saturated materials compared to the dry material. Understanding the fracture mechanisms that control the propagation of cracks through saturated, partially saturated and dry particulate materials comprised of colloidal sized particles provides additional insight into understanding drying cracks in paint, other coatings, ceramics and water treatment sludge.

\section{Introduction}

Wet particulate materials comprised of colloidal sized particles are associated with a range of industries and applications; from waste water sludge filtration and minerals processing, to paints and coatings, and the fabrication of advanced ceramics. An inevitable stage during the processing or application of such wet particulate materials will be that of drying, which can cause cracking of the particulate material. ${ }^{1-6}$ Such cracking is detrimental to most applications like paint and ceramics, but can be helpful in dewatering sludges. In the natural environment, such cracking commonly occurs when a lake dries out resulting in "mud cracks". 7, 8 Our general understanding of such phenomena has advanced significantly in the past couple of decades. ${ }^{3,4}$, 9-14 Despite these advances, the key material property that controls whether or not cracking will occur, i.e., the fracture toughness, has received little attention.

Curved liquid menisci between the particles on the surface of the drying particulate material produce a compressive consolidation stress on the particle network ${ }^{6,15-17}$. This causes the particle network to consolidate and increase its density. Shrinkage of the drying surface that is constrained by either a solid substrate or underlying material which is not shrinking, results in the development of tensile stress at the surface that is the cause of cracking. Cracking of these particulate bodies has been found to usually occur during the final stage of drying ${ }^{1,3-}$ 5,12 for slow drying, but may occur earlier during fast drying ${ }^{6,17}$. When the rate of evaporation exceeds the rate at which liquid within the pore network can be transported to the surface, the particulate body will undergo fast drying. ${ }^{17}$ Controlling the conditions to induce slow drying, where the rate of evaporation is less than the rate of liquid flow through the pore network, will result in uniform shrinkage of the body reducing the tensile stresses that lead to cracking.

Work on drying cracking has focused on measuring the drying stress $3,9,10,18$ and determining the critical thickness. ${ }^{9}, 10$ Further work on the drying of films showed that additions of organic molecules such as binders and plasticizers reduced the drying stresses. ${ }^{3,12}$ Surfactants were able to reduce the surface tension in the liquid phase that reduced the capillary pressure through the film - further reducing drying stresses. ${ }^{4}, 10$ Moreover, the mechanical properties of the colloidal particles have been shown to effect the crack formation of drying films, where the softer particles were able to deform thereby reducing the extent of the cracking. ${ }^{19}$ The study of the spacing of cracks and crack patterns in the drying of particulate materials has also been investigated. ${ }^{20-23}$

The strength and fracture behaviour of dry granular materials and powder compacts are also of interest, since these materials are often used in areas of ceramic and metal powder processing, pharmaceutical and ceramic dental crowns. However, mechanical testing of such materials is limited by the configurations available that can accommodate their mostly brittle behaviour or inability to handle gripping devices. Uniaxial compression of dry brittle ceramic powder compacts has been common for some time. ${ }^{24,25}$ The diametral compression test, also known as the Brazilian disk test, has been used as a means of indirectly measuring the tensile strength of a range of materials sensitive to normal tensile testing conditions for the aforementioned reasons. The test compresses either a cylinder (plane strain) or disk (plane stress) in the diametral plane, i.e., along the diameter, to impart a tensile stress orthogonal to the loading direction, as described in more detail in the fracture toughness determination section. The diametral compression test has seen successful application in measuring the tensile strength of dried powdered compacts ${ }^{26-29}$ and moist agglomerate mixtures ${ }^{30}$, whereby the effect of various binder additives and compaction conditions are of interest on the materials tensile failure strength. Furthermore, this test has been adapted to measure the fracture toughness by introducing a centralised flaw. ${ }^{31}$ By simple alignment of the internal flaw with respect to the loading direction, either tensile opening (mode I), in-plane shear (mode II) or mixed mode I and II fracture toughness can be determined. ${ }^{32}$, 33 Extensive application of the diametral compression test in measuring fracture toughness has mostly been in the areas of sintered ceramics $^{34-37}$ and rocks. ${ }^{38,}{ }^{39}$ However, some work has been carried out that studied the effect of binder and compaction conditions on the fracture toughness of powder compacts. ${ }^{40,41}$ 
The characterization of mechanical behaviour of wet particulate materials is less common, albeit there is a large body of knowledge on the flow of colloidal suspensions and gels. ${ }^{42,43}$. Uniaxial compression has been used to measure peak ${ }^{44}$, flow ${ }^{44,}$ 45 and yield stresses ${ }^{46}$ of saturated powder compacts. Triaxial compression testing is commonly used in the soil mechanics field, ${ }^{47,} 48$ although this provides information about consolidation and yield strength rather than toughness. Quantifying the fracture toughness of saturated particulate materials has received little attention, however, progress has been made in modelling the role of plasticity on the rate of crack growth in drying pastes. ${ }^{49}, 50$ Sarkar and Tirumkudulu ${ }^{51}$ measured the ultimate strength of colloidal dispersions forming a relationship between the critical stress to nucleate cracks and flaw sizes. Goehring et al. ${ }^{52}$ studied the role of plasticity on the cracks formed during the drying of colloidal films. It was shown that the plastic deformation that occurred around the crack tip was caused by particle rearrangement and microcracking, and suggested that increasing the fracture toughness of such films could be achieved by decreasing the yield stress of the suspensions. Sengupta and Tirumkudulu ${ }^{53}$ studied the dynamic behaviour of colloidal films by casting suspension between two wires and measuring the deflection during drying. The critical cracking stress was found to vary inversely to the $2 / 3$ power of the film thickness, while the crack velocity was estimated as being a function of the various energies involved in crack propagation and the viscous dissipation of the fluid within the pore network. Recently, Birk-Braun et al. ${ }^{54}$ have developed a clever method to estimate the ratio of fracture toughness to modulus, which will be useful in situations where these two parameters cannot easily be independently measured.

The objective of the current study is to develop a method for testing saturated and dry particulate materials comprised of colloidal sized particles and investigate the effect of saturation on the fracture toughness. The materials of interest in this work are solid-like in behaviour in both the wet and dry state. They have sufficiently high yield stress that they do not slump under their own weight, can be handled and can be tested in diametral compression. In the dry state the van der Waals attraction between particles is sufficient to provide cohesion that exceeds the body forces. In the wet state, the bodies are between 80 to $90 \%$ saturated. Although the individual particles interact via electrical double layer repulsion, there is a touching particle network ${ }^{55}$ that provides a skeleton with sufficient strength to support the nearly saturated body. The method directly and independently measures fracture toughness and elastic modulus, which in the long run is likely to prove more robust than indirect measurements. Developing a test to determine the fracture toughness of both saturated and dry particulate materials requires careful consideration. The diametral compression test offers several benefits over other methods used to measure fracture toughness. For instance, dry particulate bodies are known to be extremely brittle, even more so without the addition of binders, whereas the saturated materials will exhibit a degree of elastic-plastic deformation, particularly at the points of contact. Conventional geometries such as notched bars ${ }^{56}$ or compact tension geometries ${ }^{57}$ are difficult to produce from wet materials that do not have high enough yield stress to hold their own shape under handling and gravity. The screw method used in soil mechanics ${ }^{58}$ is also not suitable for both wet and dry materials and is not soundly based on fracture mechanics first principles. The diametral compression test can be used to apply a tensile stress to the centre of a disk via compression applied at two contact lines along the diametral axis. The line loads will spread out over a contact area, which will vary depending on the yield strength of the material. The distributed load can be accounted for in determining the fracture stress. Furthermore, gripping of the sample is not required, which would prove especially difficult for wet and soft materials. A method that applies a modification of linear elastic fracture mechanics, ${ }^{59}$ whereby an effective crack length was introduced to account for mechanisms of plastic deformation, was used to determine the mode I fracture toughness.

\section{Experimental Procedure}

\section{Sample preparation and characterisation}

Aqueous suspensions were prepared from high purity alphaalumina powder (AKP-15, Sumitomo Chemical Co. Ltd, Tokyo Japan) with a mean particle diameter of $0.7 \mu \mathrm{m}$. Particle size distributions and SEM images of the powder can be found in the literature ${ }^{44}$. Three suspensions were prepared containing 0.35 , 0.50 and 0.60 volume fraction of solids, which were dispersed at $\mathrm{pH} 4.0( \pm 0.1)$ using analytical grade $\mathrm{HNO}_{3}$ followed by ultrasonic dispersion (Misonix Sonicators S-4000, Newtown CT, USA).

Samples were slip cast on plaster of Paris boards by pouring the suspensions into aluminium cylindrical shaped moulds with a diameter (2R) of $34.5 \mathrm{~mm}$. Figure 1 shows an annotated photograph of the moulds and a typical sample. The amount of suspension cast was pre-determined for each solids volume fraction so that a consolidated cylinder thicknesses of approximately $8 \mathrm{~mm}$ resulted in each case. This thickness was selected as it allowed for tests to be carried out under plane stress conditions, without encountering alignment difficulties experienced with testing thinner specimens. Flaws were cast into the specimens using aluminium inserts. The elongated diamond shaped aluminium inserts (see Figure 1) were attached to the top of the cylindrical moulds so they sat flush with the plaster resulting in a sample with a through thickness flaw. The length of the flaw (2a) was varied between $3.45 \mathrm{~mm}$ and $17.25 \mathrm{~mm}$. Flaws with four different non-dimensional crack lengths $(a / R)$ were produced when the aluminium inserts were removed from the cast cylinders. The diamond shaped aluminium inserts were machined such that the tips at either end comprised a diameter of $0.5 \mathrm{~mm}$. The width of the flaw at its widest point i.e., the centre of the disk is $1.25 \mathrm{~mm}$. The casting time, i.e., from when the suspension was poured into the mould, to when it was removed from the plaster board and aluminium cylinder, depended on the initial concentration of the suspensions as follows: 0.5 hours for 0.6 volume fraction, 0.75 hours for 0.5 volume fraction and 3.5 hours for 0.35 
volume fraction. The mould was covered with cling wrap to prevent water loss from the top surface of the casting. In addition, to prevent moisture loss between demoulding and mechanical testing of the saturated specimens, which was never greater than 1 hour, each sample was placed in a zip-tie bags containing saturated paper towel. The mechanical tests on the dry samples were conducted after drying in an oven for 24 hours at $80^{\circ} \mathrm{C}$. It should be noted that this method of drying removed all liquid from the samples. This was confirmed via tests whereby samples were heated for an additional 1 hour at $500^{\circ} \mathrm{C}$ and found to have less than $0.04 \%$ difference in weight compared to the samples dried at $80^{\circ} \mathrm{C}$.

The relative density and saturation for the samples were measured via the weight difference method, where the volume of water contained within the wet bodies was determined by weighting a set of samples after demoulding, then after drying for a minimum of $24 \mathrm{hrs}$ at $80^{\circ} \mathrm{C}$. Archimedes' method using wax coating of the powder compacts was used to determine the relative density of the dried cast cylinders as described in prior work $^{60}$. Using this information and the weight loss during drying, it was possible to determine the fraction of saturation.

The Young's modulus (E) was determined for both wet and dry samples for the various volume fraction of solids samples by measurement of the ultrasonic wave velocity via the through transmission technique (Pundit 200, Proceq SA, Zürich, Switzerland). The samples were $34.5 \mathrm{~mm}$ in diameter and $15 \mathrm{~mm}$ thick. This method was chosen as it has exhibited robust results for porous and dense particulate ceramics ${ }^{61}$ and wet alumina films during drying ${ }^{4}$ measured by other researchers.

\section{Fracture Toughness Determination}

The fracture toughness or critical stress intensity factor $\left(K_{I C}\right)$ is determined from the measured fracture stress, the flaw size and a geometry factor as described below. Diametral compression was carried out on an Instron ${ }^{\circ} 5848$ MicroTester $^{\mathrm{TM}}$ with a $2 \mathrm{kN}$ loadcell (Instron - Illinois Tool Works Inc., Norwood MA, USA). The diametral compression test, also known as the Brazilian disk test, loads disk shaped specimens along their diameter to generate a biaxial stress state within the sample. Figure 2 shows a schematic of the test procedure for vertical loading along with the corresponding coordinate system.

The analysis is based on the assumption of a homogeneous, isotropic, linear elastic material. A particulate material comprised of colloidal sized particles produced by slip casing from a well dispersed suspension is expected to be homogeneous on a macroscopic length scale relevant to the crack extension (many orders of magnitude larger than the particle size). Objects cast from well dispersed slurries without additional pressure are known to be isotropic. ${ }^{62}$ Wet particulate materials are generally viscoelastic rather than linear elastic. However, for the samples produced in this work, the high particle concentration produced materials with storage moduli several orders of magnitude larger than loss moduli such that they behave like solids. ${ }^{63-67}$ Based on this knowledge, we conclude the assumptions of homogeneous, isotropic and linear elastic material are reasonable for our investigation. We discuss later the role of plasticity beyond the limit of elasticity.

Compressive principle stresses are produced in the direction of the load and transverse principle tensile stresses perpendicular to the load, with the shear stresses along the diameter parallel to the loading direction being zero. At the centre of the disk, the stresses are at a maximum; assuming line contact load, the magnitude of the elastic stresses derived from theory by Hertz ${ }^{68}$ are;

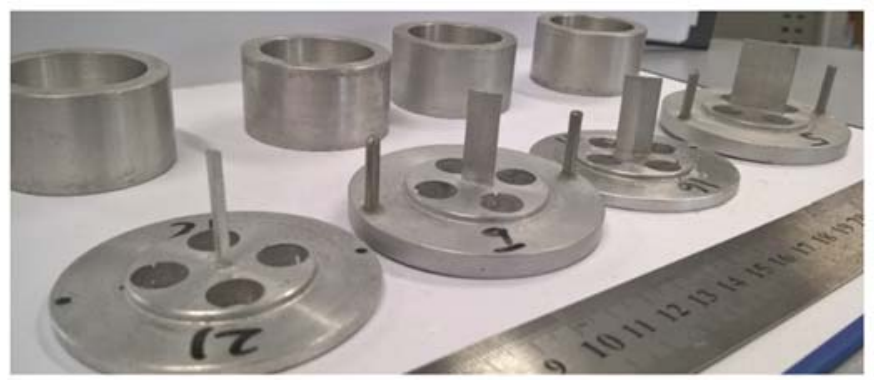

$$
\sigma_{x}=\frac{2 P}{\pi D t}
$$
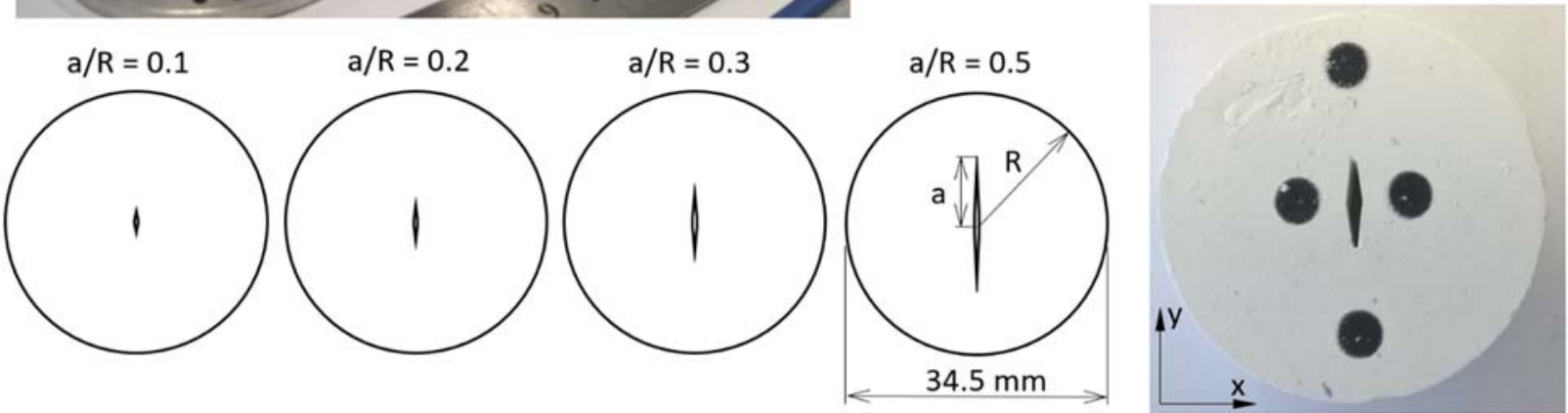

Figure 1. Photographs showing the cylindrical moulds and machined aluminium flaw formers (top). The cylinders are $34.5 \mathrm{~mm}$ in diameter and approximately $8 \mathrm{~mm}$ thick. The scale of the ruler is in centimetres. Details of the four dimensionless crack lengths used in this study (bottom left) and sample before diametral compression testing with a cast crack (bottom right). The four dots on the sample are used by the non-contact extensometer to track axial and transverse extensions. 
(a)

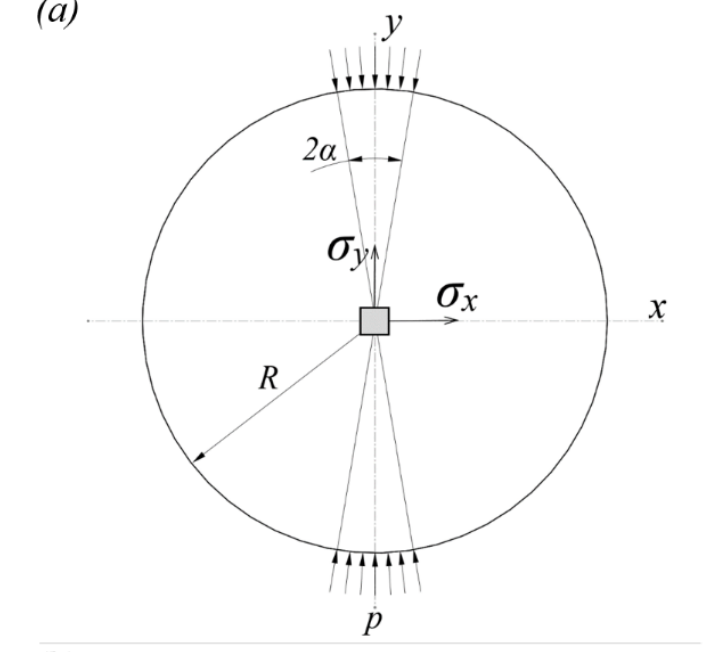

(b)

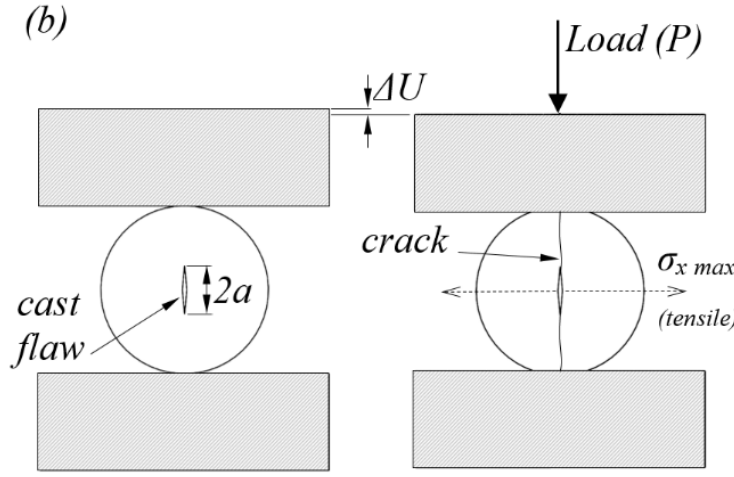

Figure 2. Schematic showing the geometry and coordinate system (a) of the diametral compression test (b). $p$ is the pressure acting on the flattened area due to the applied load $P, \alpha$ is the half angle of the flattened area. $\Delta U$ is the displacement and $a$ is half the cast flaw length.

$$
\sigma_{y}=-\frac{6 P}{\pi D t}
$$

where $\sigma_{x}$ is the stress in the direction perpendicular to the loading direction (horixontal), $\sigma_{y}$ is the stress in the direction parallel to the loading direction (vertical), $P$ is the compressive load, $D$ is the diameter and $t$ the disk thickness.

In practice, however, specimens exhibiting at least a degree of elastic-plastic behaviour subjected to diametral compression have their load distributed over finite areas at the two lines of contact. In these cases, the simple calculation of the stresses presented in equations 1 and 2 are not valid so more accurate calculations need to be used as described next. The distribution of load also ensures the specimens do not fail by the initiation of excessive compressive or shear stresses at the interface. ${ }^{69,26}$

Hondros $^{70}$ presented complete solutions of stress as a function of position for diametrally compressed specimens with distributed loads valid for both plane stress (disk) and plane strain (cylinder) loading conditions. In the plain stress case, such as for the sample geometry used in the present investigation, the stresses along the diameter (vertical) parallel to the loading direction as per the schematic in Figure 2(a), are given as:

$$
\begin{gathered}
\sigma_{x}=+\frac{2 p}{\pi}\left[\frac{\left(1-\frac{r^{2}}{R^{2}}\right) \sin 2 \alpha}{1-\frac{2 r^{2}}{R^{2}} \cos 2 \alpha+\frac{r^{4}}{R^{4}}}-\tan ^{-1} \frac{\left(1+\frac{r^{2}}{R^{2}}\right)}{\left(1-\frac{r^{2}}{R^{2}}\right)} \tan \alpha\right] \\
\sigma_{y}=-\frac{2 p}{\pi}\left[\frac{\left(1-\frac{r^{2}}{R^{2}}\right) \sin 2 \alpha}{1-\frac{2 r^{2}}{R^{2}} \cos 2 \alpha+\frac{r^{4}}{R^{4}}}+\tan ^{-1} \frac{\left(1+\frac{r^{2}}{R^{2}}\right)}{\left(1-\frac{r^{2}}{R^{2}}\right)} \tan \alpha\right] \\
\tau_{x y}=0
\end{gathered}
$$

where: $p$ is the applied load expressed as pressure, $\alpha$ is the arc contact angle and $r$ is the location along y axis. Equations 3 to 5 were derived from those presented by Hondros ${ }^{70}$ where the author presents more complete solutions for any location along the principle axes in the diametrally compressed samples as presented in the Supplementary material section. The effect of the angular width $2 \alpha$ on the stresses along the vertical diameter is shown in Figure 3. At the centre of the disk, an increase in the angular loading width results in greater tensile stresses perpendicular to the diametral plane along which the crack extends. Inherently, it is this stress acting in the centre of the disk along the $x$ axis that leads to the failure of the specimens containing flaws. However, moving away from the centre of the disk along the $y$ axis the stress $\sigma_{x}$ becomes compressive, with the transition point progressing further away from the loading areas at the outer diameter as the angular width increases.

The contact width between the sample and platens of the diametral compression tests was recorded with dual layer pressure sensing film (Sensor Products Inc. Madison, NJ USA). As load is applied to the $0.19 \mathrm{~mm}$ thick film, microcapsules attached to one layer rupture marking the other layer with a dark colour. This procedure not only provides the benefit of recording an accurate contact width ${ }^{71}$, but any uneven contact that was present at the point of failure can be detected. The typical contact widths for dry and wet samples were between 1.5-2.5 mm (2-4 $\left.{ }^{\circ}\right)$ and 3.5-5.5 $\mathrm{mm}\left(12-20^{\circ}\right)$, respectively. Simple geometry is used to convert the measured widths to arc contact angles $(\alpha)$ so that equation 3 can be used to determine the cracking stress.

Aligning the cast flaw parallel to the load in a diametral compression test will yield the required conditions for pure mode I fracture, i.e., tensile fracture. Solutions for determining the fracture toughness, or the critical value of the stress intensity factor (SIF) $K_{I c}$, for a disk in diametral compression have been reported by a number of authors ${ }^{32,33,72}$. This study will apply the solution presented by Atkinson et al. ${ }^{33}$, which for a pure mode I type loading condition can be written as;

$$
K_{I c}=\sigma_{f} F_{I} \sqrt{\pi a}
$$


where $\sigma_{f}$ is the failure stress, $a$ is the half crack length as per Figure 1 and Figure 2, and $F_{I}$ is the non-dimensional shape coefficient for mode I loading that is a function of the angle $\psi$ with respect to the loading direction and crack-diameter ratio $a / R(\psi=0$ in the present work). A complicated infinite series solution for $F_{I}$ was provided by Atkinson et al. ${ }^{33}$. However, the authors also provided a simplified five-term truncation of the complicated series for relative crack sizes in the range $0.1<a / R<0.6$, which has been shown to be adequate for most practical applications ${ }^{34}$ - details of which are provided in the supplementary material. The $F_{I}$ values used are 1.015 for $a / R=0.1,1.060$ for $a / R=0.2,1.356$ for $a / R=0.3,1.387$ for $a / R=0.5 . K_{I c}$ is calculated from the $F_{I}$ value, the measured fracture stress and the flaw length using equation 6 .

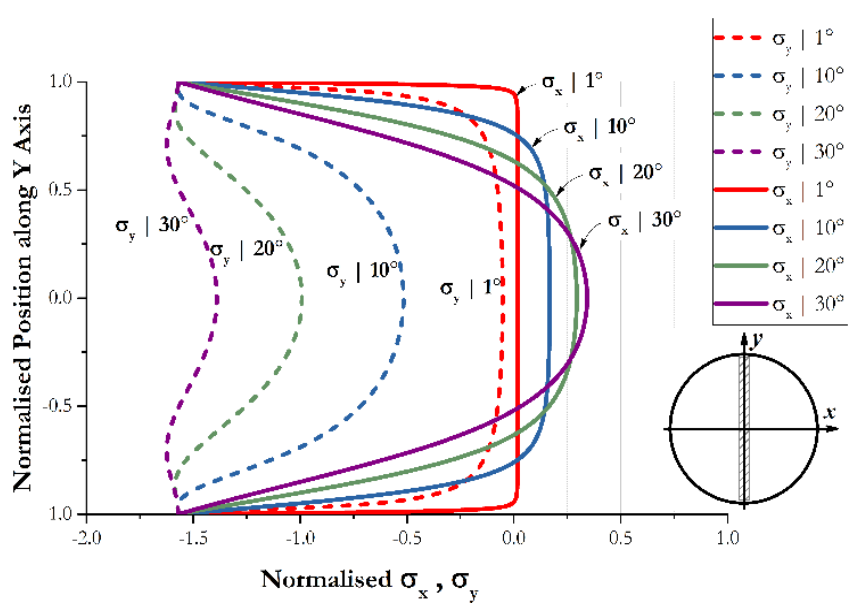

Figure 3. Stress distribution along the vertical diameter for angular contact widths of; $1^{\circ}, 10^{\circ}, 20^{\circ}$ and $30^{\circ}$. Note: The axes values of stress have been normalised to $2 \mathrm{p} / \pi=1$.

\section{Results and Discussion}

After slip casting, when the materials were still wet, they were found to be solid-like in behaviour. They have sufficiently high yield stress that they do not slump under their own weight, can be handled and can be tested in diametral compression. In the wet state, the bodies are between 80 to $90 \%$ saturated (see Table 1). Although the individual particles interact via electrical double layer repulsion, there is a touching particle network ${ }^{55}$ that provides a skeleton with sufficient strength to support the nearly saturated body. The degree of saturation of the bodies places them in the funicular region rather than the pendular region. ${ }^{73,74}$ In the pendular region it is possible that capillary forces produce adhesion between particles, but in the funicular region such capillary adhesion is negligible. After drying, the van der Waals attraction between particles is sufficient to provide cohesion that exceeds the body forces.

Figure 4 shows typical load-extension curves for the wet and dry diametrically compressed specimens. Both were cast from suspension with 0.6 volume fraction solids with dimensionless crack lengths of 0.2 . The load-displacement curves for both samples exhibit multiple stages as have been previously described for diametral compression of powdered compacts ${ }^{75}$ and rock $^{76}$. When the peak load is reached, the crack transitions from a moderate propagation rate to rapid unstable growth. Although not shown in Figure 4 in order to conserve the fracture surfaces, the load of diametrically compressed samples will continue to fluctuate after failure due to the loading of now two halves ${ }^{26}$. The brittle fracture experienced in the dry samples is illustrated by the abrupt drop in load after an extension of just $0.056 \mathrm{~mm}$. The wet sample on the other hand exhibited an extended linear region prior to the onset of unstable crack growth at an extension of $0.40 \mathrm{~mm}$.

The initial response of the load extension curves in Figure 4 highlight the different behaviour of the wet and dry materials. The dry sample exhibits an initial non-linear stiffening response, which is to be expected for materials that do not plastically

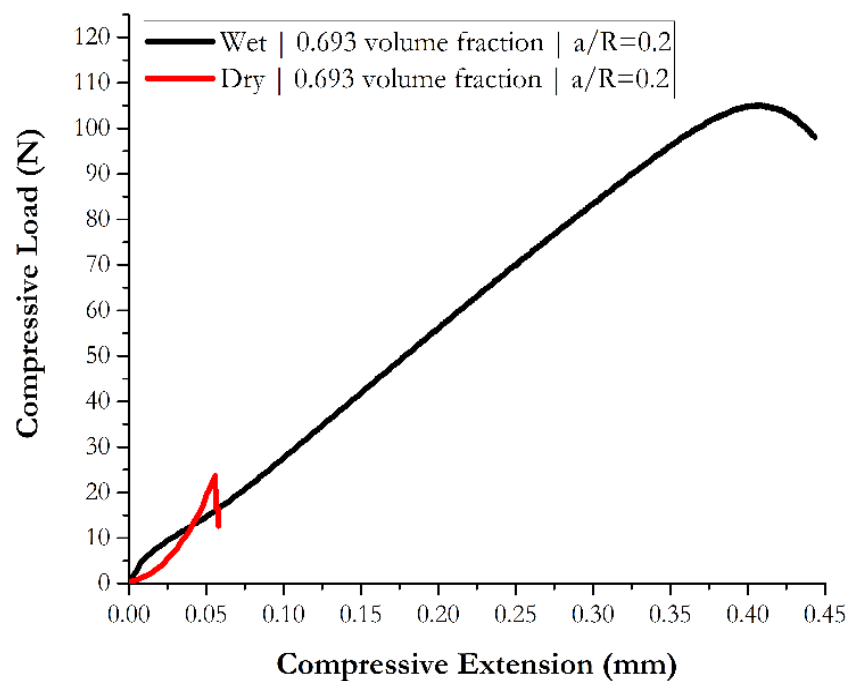

Figure 4. Load-displacement curves of wet and dry samples from the diametral compression test. Both samples were cast from suspensions of 0.6 volume fraction solids and the dimensionless crack length of the cast flaws was 0.2 .

deform. As the dry sample is loaded, the contact areas or number of contacts within the particle network would slightly increase resulting in the initial portion of the curve. The slope of the curve then increases after this initial stiffening, showing an almost linear behaviour, to the point of fracture.

The initial nonlinear softening response displayed in the wet sample may have been due to the locking of the particle network skeleton. Then the following softening response was possibly the result of one or multiple occurrences such as; (i) breakdown of the skeleton ${ }^{55}$, (ii) lubrication from the moisture content of the sample at the contact area that created a slipping motion, and/or (iii)localised flow of the particle network that most likely also occurs at the contact areas.

Figure 5 displays the typical fracture surfaces of diametrically compressed wet and dry specimens. The wet 


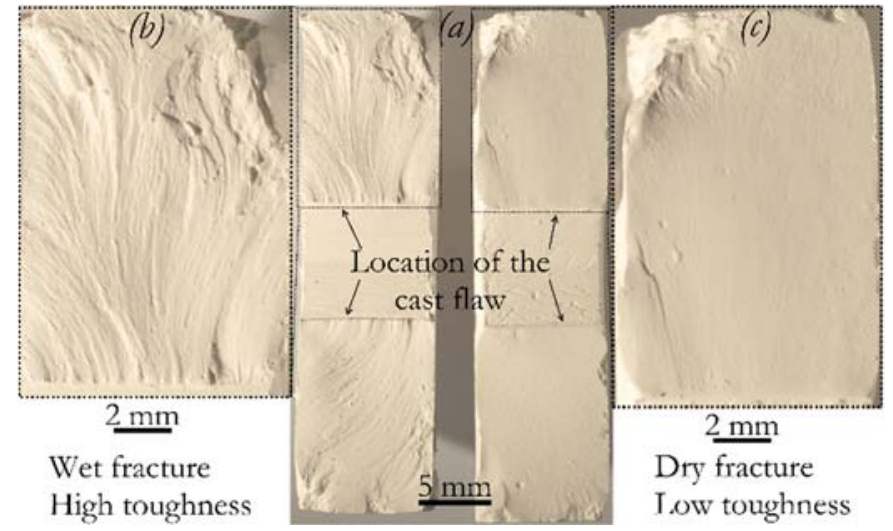

Figure 5. Typical fracture surfaces of wet and dry diametrically compressed samples. (a) shows a side by side cross section comparison of the wet and dry samples, (b) a macro image of the wet fracture surface that exhibited wavy surface and high toughness and (c) a macro image of the dry fracture surface that exhibited smooth surface and low toughness.

sample in Figure 5(b) is characterised by a rough wavy surface typical of ductile fracture, where the particulate materials have undergone a degree of flow or plastic deformation ahead of the propagating crack tip. Whereas the dry sample in Figure 5(c) displays an almost perfectly flat surface on the macro scale consistent with brittle fracture, exhibiting little to no plastic deformation before failure. These observations are consistent with those made by $\mathrm{Yu}$ and Lange for wet and dry alumina powder bars tested in three point bending. ${ }^{77}$

Figure 6 shows the results of the mode I fracture toughness for the wet and dry samples with respect to the dimensionless crack length. There is little difference between the samples produced from the different volume fraction of solids suspensions with most of the data points falling within the error bars that represent \pm 1 standard deviation. This is primarily because the consolidation during slip casting of the well dispersed suspensions resulted in similar final solids concentrations of the samples produced from the three different initial solids content suspensions. The solids volume fraction of the bodies cast from $0.35,0.5$ and 0.6 volume fraction suspensions was $0.674,0.679$ and 0.693 volume fraction respectively. However, there is a significant difference between the wet and dry samples, with wet samples exhibiting a significant increase in toughness over the dry samples consistent with the higher strength observed for wet samples by $\mathrm{Yu}$ and Lange. ${ }^{77}$ The same trends, particularly higher toughness when wet compared to dry, were also found in another particulate material system, namely, calcium carbonate with a $d_{50}$ of approximately $2 \mu \mathrm{m}$ as presented in the supplementary material. However, the reader may be surprised to see the increasing trend of fracture toughness with increasing dimensionless crack length, since the fracture toughness of a material should be independent of $a / R$. This trend is seen in several other investigations ${ }^{59,78,79}$ and can be explained by reference to the work of Adams et al. ${ }^{59}$. As shown in Figure 3, the stress in the $x$ direction (horizontal) is tensile at the centre of the disk. The stress near the loading area is compressive. As the contact area increases due to flattening, the compressive stress region extends farther from the outer

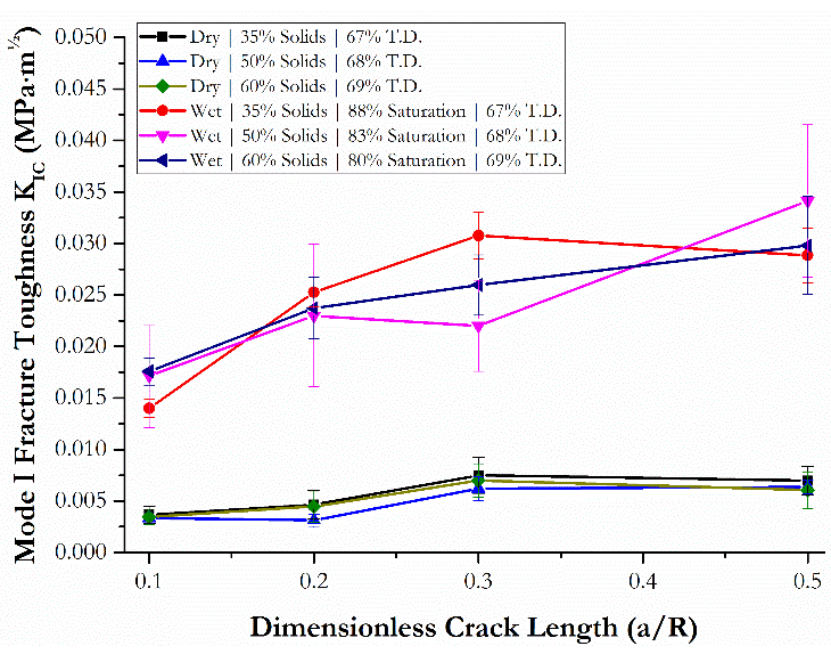

Figure 6. Mode I fracture toughness as a function of the dimensionless crack length for wet and dry samples cast at varying solids volume fraction.

diameter towards the centre of the disk. The longer flaws will have a reduced tensile stress at their tips and become influenced by the compressive stress near the contact areas. Thus the calculated failure stress is greater than the actual stress at the crack tip when the sample fractures. ${ }^{80}$

According to Adams et al. ${ }^{59}$ one can determine the flaw size independent critical stress intensity factor as follows. Rearranging equation (6) results in

$$
\left(\sigma_{f} F_{I}\right)^{2}=K_{I c}^{2} \frac{1}{\pi a}
$$

If one plots $\left(\sigma_{f} F_{I}\right)^{2}$ as a function of $1 / a$, one would expect a straight line with slope equal to $K_{I c}^{2} / \pi$. As shown in Figure 7 the black square data points do not follow a straight line. Adams et al. ${ }^{59}$, using Irwin's ${ }^{81}$ modification for ductile materials, suggests that the non-linearities in the data can be accounted for by assuming there is a process zone of radius $\Delta a$ that is on order of the size of the plastically deformed region ahead of the crack tip. An iterative procedure is used to determine the process zone size and the flaw size independent fracture toughness. The first step involves plotting $\left(\sigma_{f} F_{I}\right)^{2}$ as a function of $1 / a$. The best fit to the data is a curve as shown in Figure 7. The first estimate of $K_{I c}$, i.e., $K_{I c}^{(0)}$, is deduced from the initial linear slope of the first three data points. Then substituting $K_{I c}^{(0)}$ back into equation (6) with the failure stress $\sigma_{f}$, an effective crack length $(\bar{a}=a+\Delta a)$ is determined. The first estimate of $\Delta a$ is obtained, i.e., $\Delta a^{(0)}$ by subtracting $a$ from $\bar{a}$. The next iteration follows the same procedure, however, $\left(\sigma_{f} F_{I}\right)^{2}$ is now plotted 


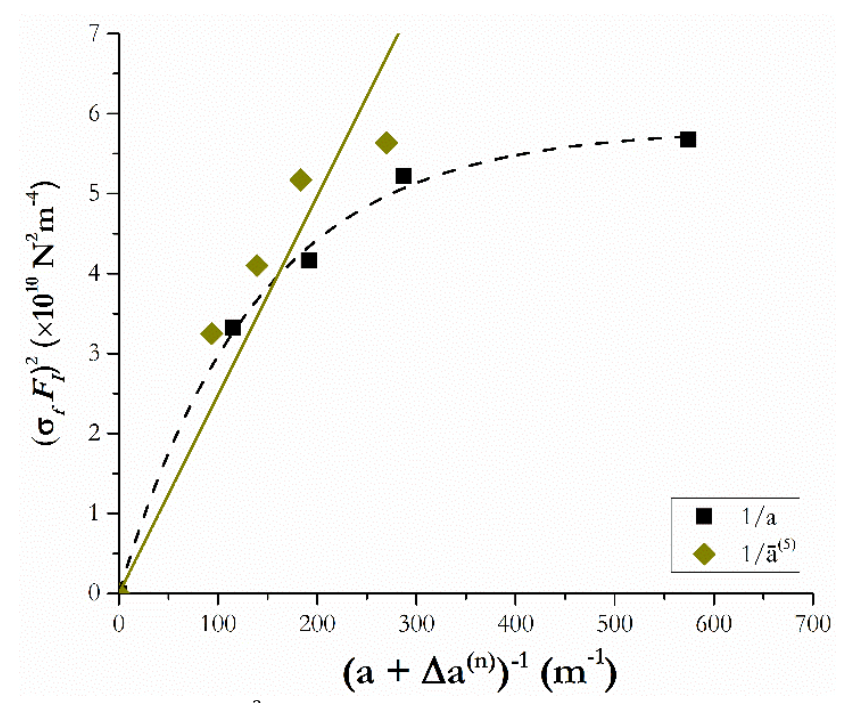

Figure 7. Plot of $\left(\sigma_{f} F_{I}\right)^{2}$ as a function of the reciprocal crack length $(a)^{-1}$ (square symbols) and the reciprocal effective crack length $(\bar{a})^{-1}$ after 5 iterations, i.e., $\left(a+\Delta a^{(5)}\right)^{-1}$

as a function of $\left(a+\Delta a^{(0)}\right)^{-1}$. The process is repeated until the solution converges and the best linear fit is achieved as shown in Figure 7 with the green diamonds after 5 iterations. This procedure was carried out for the 6 different conditions presented in Figure 6 (dry and wet for $0.674,0.679$ and 0.693 volume fraction solids samples). The slopes of the best linear fits were used to calculate the crack length independent critical stress intensity factors $\left(K_{I c}\right)$ for each of the 6 conditions as presented in Table 1 . The $K_{I C}$ values for the wet samples are about five to six times higher than for the corresponding dry samples.

The fracture toughness of the dry samples did not follow any trend with respect to the solids concentration over the narrow range investigated, 0.674 to 0.693 volume fraction. (Note the narrow range of volume fraction solids investigated resulted from the consolidation of suspensions ranging from 0.35 to 0.6 volume fraction. This is not surprising because the suspensions were well dispersed and such suspensions are known to consolidate to close to the maximum packing fraction even under relatively low consolidation pressures such as during slip casting ${ }^{55}$ ). As presented in Table 1 the saturation of the samples increased from $80 \%$ to $88 \%$ as the concentration of the
For the dry samples the process zone was found to be less than $0.1 \mathrm{~mm}$. The lack of any significant process zone is consistent with the smooth fracture surface indicative of brittle fracture shown in Figure 5(c). As shown in Table 1, the process zone of the wet samples was found to be between 2.0 and 5.8 $\mathrm{mm}$. The larger process zone of the nearly saturated samples compared to the dry samples is consistent with the significantly higher fracture toughness of the nearly saturated samples. The existence of the process zones in the nearly saturated samples is also consistent with the fracture surface shown in Figure 5(b) typical of ductile fracture. The nearly saturated samples are expected to have a finite yield stress which is less than the fracture stress. The increased process zone size and increased toughness of the nearly saturated samples are likely due to a decrease in yield stress of the material as saturation increases. It is well known that the yield stress of suspensions decreases with increasing liquid content. ${ }^{42,43,82}$

The plastic zone needs to be confined by the un-yielded material surrounding it to enable the application of linear elastic fracture mechanics (LEFM). The theory of linear elasticity is considered valid so long as the process zone size is less than all relevant length scales, particularly the sample dimensions. The largest process zone was found to be $5.8 \mathrm{~mm}$ in diameter. For the largest crack length of $17.25 \mathrm{~mm}(a / R=0.5)$, this process zone is less than all relevant dimensions; such as thickness ( 8 $\mathrm{mm})$, crack length $(\mathrm{a}=8.625 \mathrm{~mm})$ and ligament length $(8.625$ $\mathrm{mm})$. In cases where the crack length is smaller, the ligament length increases, thereby increasing the distance from the end of the process zone to the edge of the sample where fracture occurs. In addition, assuming a cylindrical process zone and accounting for the sample thickness, the volume of the process zone is much smaller than the volume of material being tested. Therefore, the process zone is confined by the un-yielded material surrounding it. Although on the border of being considered acceptable for LEFM, such sample dimensions are commonly used to measure the fracture toughness of polymer materials. ${ }^{83-86}$ These studies in this well-established field also apply similar methods of LEFM to determine a process zone size and intrinsic fracture toughness.

The Young's modulus $(E)$ values determined from the ultrasonic measurements are presented in Table 2. The Young's moduli of the dry samples increase slightly as a function of solids content as observed previously. ${ }^{87,88}$ The Young's moduli for the

Table 1. Results of for the Mode I fracture toughness of wet and dry samples employing the iteration procedure to account for the flaw length dependence by the introduction of a process zone representing the area of plastic deformation.

\begin{tabular}{|c|c|c|c|c|c|c|c|}
\hline \multirow[b]{2}{*}{$\begin{array}{l}\text { Solids } \\
(\mathrm{vol} \%)\end{array}$} & \multicolumn{4}{|c|}{ Wet } & \multicolumn{3}{|c|}{ Dry } \\
\hline & $\begin{array}{c}\text { Mode I Fracture } \\
\text { Toughness } \boldsymbol{K}_{\boldsymbol{I c}} \\
\left(\mathrm{MPa} \cdot \mathrm{m}^{1 / 2}\right) \\
\end{array}$ & $\begin{array}{c}\text { Process Zone } \\
(\mathrm{mm})\end{array}$ & $\begin{array}{c}\text { Saturation } \\
(\%) \\
\end{array}$ & $\begin{array}{l}\text { Solids Volume } \\
\text { fraction }\end{array}$ & $\begin{array}{l}\text { Mode I Fracture } \\
\text { Toughness } \boldsymbol{K}_{\boldsymbol{I} \boldsymbol{c}} \\
\left(\mathrm{MPa} \cdot \mathrm{m}^{1 / 2}\right)\end{array}$ & $\begin{array}{l}\text { Process Zone } \\
(\mathrm{mm})\end{array}$ & $\begin{array}{l}\text { Green Density } \\
\left(\mathrm{g} / \mathrm{cm}^{3}\right)\end{array}$ \\
\hline 35 & 0.0370 & 5.8 & 87.7 & 0.674 & 0.0059 & $<0.1$ & 2.677 \\
\hline 50 & 0.0282 & 2.3 & 83.0 & 0.679 & 0.0040 & $<0.1$ & 2.697 \\
\hline 60 & 0.0279 & 2.0 & 80.2 & 0.693 & 0.0056 & $<0.1$ & 2.750 \\
\hline
\end{tabular}

suspension used in casting, decreased from 0.6 to 0.35 volume fraction. Although increased saturation is likely to result in increased toughness, there is no significant trend over the saturated samples show the opposite trend with solids content that is likely due to the increasing saturation level of the samples with lower particle content. 89,90 
The critical stress intensity factor in plane stress conditions can be related to the critical strain energy release rate through the relationship established by $\operatorname{Irwin}^{91}$ :

$$
G_{I C}=\frac{K_{I C}^{2}}{E}
$$

where $G_{I c}$ is the critical strain energy release rate. The critical strain energy release rate was calculated from the measured values of $E$ and $K_{I C}$ and presented in Table 2. The Griffith's ${ }^{92}$ energy criteria for fracture states that the strain energy released must equal the energy required to create the two new surfaces. Even for very brittle materials such as glass and ceramics, the fracture energy is actually greater than that needed to create the new surfaces. ${ }^{93-96}$ The energy needed to create the new surfaces is a minimum bound and in most cases other dissipation mechanisms exist which increase the fracture toughness of the material. Irwin ${ }^{97}$ and Orowan $^{98}$ modified Griffith's theory to include dissipation due to plastic deformation in metals. The revised expression for the critical strain energy release rate includes a term for plastic dissipation and is;

$$
G_{I c}=2 \gamma+\gamma_{p}
$$

where $\gamma$ is the surface energy of the solid and $\gamma_{p}$ accounts for the additional dissipation due to plastic deformation or flow that occurs in front of the crack tip. $\gamma_{p}$ depends on the yield stress of the material, the volume of material plastically deformed and the strain within the deformed area. ${ }^{99}$

Assuming that there is no additional dissipation, aside from creating the new surfaces in the dry samples, we can take $2 \gamma$ as the value of $G_{I C}$ for the dry sample such that $2 \gamma$ is between 0.0051 and $0.0111 \mathrm{~J} / \mathrm{m}^{2}$. By subtraction, $\gamma_{p}$ is between $0.1002 \mathrm{~J} / \mathrm{m}^{2}$ and $0.1620 \mathrm{~J} / \mathrm{m}^{2}$ for the nearly saturated samples as shown in Table 2. These results show that the energy dissipated though plastic deformation is more than an order of magnitude greater than that needed to create the new surface area. These results also confirm the hypothesis of Goehring et $a .^{52}$, and $\mathrm{Yu}$ and Lange ${ }^{77}$ that decreasing yield stress increases the toughness of particulate materials.

The ability to measure toughness in both dry and wet particulate materials opens up the opportunity to measure the influence of various parameters on the toughness of such materials. For instance, the volume fraction of solids, particle size and structure of the particle network will be expected to be significant factors in the fracture toughness as they are in most other rheological and mechanical behavior of particulate materials. ${ }^{42,43,63,82}$ Furthermore, in wet materials the colloidal interaction forces are expected to influence the toughness since they are known to influence the yield stress. Stronger attraction will increase the yield stress and is expected to reduce the toughness. Finally, the type of material will influence the colloidal interactions via the van der Waals interaction which is different for different types of particulate solids. We have no reason to believe that any of the factors that influence the fracture toughness in the wet state will change the fact that the wet materials have higher toughness than the dry ones. The wet ones will generally have ability to plastically deform to a greater extent than dry particulate materials with otherwise the same characteristics.

Table 2. Young's modulus and critical strain energy release rate for the wet and dry samples of varying volume fraction. Included is the determined contribution of the plastic deformation/flow in the wet samples $\left(\gamma_{p}\right)$ to the fracture energy.

\begin{tabular}{cccccc}
\hline \multirow{2}{*}{ Solids } & \multicolumn{2}{c}{ Wet } & \multicolumn{2}{c}{ Dry } & \\
\cline { 2 - 5 } & $\begin{array}{c}\text { Young's } \\
\text { Modulus }\end{array}$ & $\begin{array}{c}\boldsymbol{G}_{\boldsymbol{I} \boldsymbol{c}} \\
\left(2 \gamma+\gamma_{\boldsymbol{p}}\right)\end{array}$ & $\begin{array}{c}\text { Young's } \\
\text { Modulus }\end{array}$ & $\begin{array}{c}\boldsymbol{G}_{\boldsymbol{I} \boldsymbol{c}} \\
(2 \gamma)\end{array}$ & $\boldsymbol{\gamma}_{\boldsymbol{p}}$ \\
\cline { 2 - 5 }$(\mathrm{vol} \%)$ & $(\mathrm{GPa})$ & $\left(\mathrm{J} / \mathrm{m}^{2}\right)$ & $(\mathrm{GPa})$ & $\left(\mathrm{J} / \mathrm{m}^{2}\right)$ & $\left(\mathrm{J} / \mathrm{m}^{2}\right)$ \\
35 & 7.09 & 0.1732 & 2.9 & 0.0111 & 0.1620 \\
50 & 6.2 & 0.1053 & 2.96 & 0.0051 & 0.1002 \\
60 & 5.69 & 0.1225 & 4.97 & 0.0056 & 0.1169 \\
\hline
\end{tabular}

\section{Conclusions}

A method has been developed that for the first time enables direct quantitative measurements of the fracture toughness of particulate materials over a wide range of saturations from nearly saturated to completely dry. The nearly saturated materials have significantly higher toughness than the dry materials. This is the first time such difference has been directly quantified. The fracture surfaces of the nearly saturated materials are wavy, a characteristic of ductile fracture where significant plastic deformation occurs ahead of the crack tip. The dry sample fracture surfaces are smooth indicative of brittle fracture that occurs without any significant plastic deformation of the material. Analysis of the fracture toughness measurements as a function of relative flaw length has been used to determine the size of the process zone and the flaw size independent fracture toughness. The additional dissipation due to the plastic deformation ahead of the crack tip in the wet materials compared to the dry materials is an order of magnitude, or more, greater than the energy needed to create the new surface area. These conclusions will be useful to better describe and predict drying cracks.

\section{Acknowledgements}

Thanks to the Australian Research Council for funding Discovery Project DP150102788. Thanks to Oktay Balkis and Kevin Smeaton for fabricating the moulds. Thanks to Yitong Sui for help with the experiments on calcium carbonate particles. Thanks to Anthony Stickland, Mahesh Tirumkudulu and Alex Routh for the stimulating discussions.

\section{References}

1 G.W. Scherer, J. Am. Ceram. Soc., 1990, 73, 3-14

2 Y. Holl, J.L. Keddie, P.J. McDonald, and W.A. Winnik, in Film Formation in Coatings, ed. T. Provder and M.W. Urban, American Chemical Society, Washington, DC, 2-26, July 26th, 2001 
3 P. Wedin, C.J. Martinez, J.A. Lewis, J. Daicic, and L. Bergström, J. Colloid Interface Sci., 2004, 272, 1-9

4 J. Kiennemann, T. Chartier, C. Pagnoux, J.F. Baumard, M. Huger, and J.M. Lamérant, J. Eur. Ceram. Soc., 2005, 9, 1551-1564

5 M.S. Tirumkudulu and W.B. Russel, Langmuir, 2005, 21, 49384948

6 L.A. Brown, C.F. Zukoski, and L.R. White, AIChE J., 2002, 48, 492-502

7 L. Goehring and S.W. Morris, Phys. Today, 2014, 67, 39-44

8 L. Goehring, R. Conroy, A. Akhter, W.J. Clegg, and A.F. Routh, Soft Matter, 2010, 6, 3562-3567

9 R.C. Chiu, T.J. Garino, and M.J. Cima, J. Am. Ceram. Soc., 1993, 76, 2257-2264

10 R.C. Chiu and M.J. Cima, J. Am. Ceram. Soc., 1993, 76, 27692777

11 J.A. Lewis, K.A. Blackman, A.L. Ogden, J.A. Payne, and L.F. Francis, J. Am. Ceram. Soc., 1996, 79, 3225-3234

12 P. Wedin, J.A. Lewis, and L. Bergström, J. Colloid Interface Sci., 2005, 290, 134-144

13 E. Santanach Carreras, F. Chabert, D.E. Dunstan, and G.V. Franks, J. Colloid Interface Sci., 2007, 313, 160-168

14 A.F. Routh, Rep. Prog. Phys., 2013, 76, 046603

15 R. Buscall and L.R. White, J. Chem. Soc., Faraday Trans. 1, 1987, 83, 873-891

16 A.D. Stickland, H.-E. Teo, G.V. Franks, and P.J. Scales, Dry. Technol., 2014, 32, 1614-1620

17 A.D. Stickland, Water Res., 2015, 82, 37-46

18 C. Bauer, M. Cima, A. Dellert, and A. Roosen, J. Am. Ceram. Soc., 2009, 92, 1178-1185

19 F. Boulogne, F. Giorgiutti-Dauphiné, and L. Pauchard, Oil Gas Sci. Technol. - Rev. D'IFP Energ. Nouv., 2014, 69, 397-404

20 L. Goehring, W.J. Clegg, and A.F. Routh, Soft Matter, 2011, 7, 7984-7987

21 M.I. Smith and J.S. Sharp, Langmuir, 2011, 27, 8009-8017

22 H. Cao, D. Lan, Y. Wang, A.A. Volinsky, L. Duan, and H. Jiang, Phys. Rev. E, 2010, 82, 031602

23 P. Nandakishore and L. Goehring, Soft Matter, 2016, 12, 22532263

24 H.F. Fischmeister, E. Arzt, and L.R. Olsson, Powder Metall., 1978, 21, 179-187

25 H. Kamiya, K. Isomura, G. Jimbo, and T. Jun-ichiro, J. Am. Ceram. Soc., 1995, 78, 49-57

26 P. Jonsén, H.-Å. Häggblad, and K. Sommer, Powder Technol., 2007, 176, 148-155

27 T.J. Carneim and D.J. Green, J. Am. Ceram. Soc., 2001, 84, 14051410

28 J.L. Amorós, V. Cantavella, J.C. Jarque, and C. Felíu, J. Eur. Ceram. Soc., 2008, 28, 701-710

29 J.T. Fell and J.M. Newton, J. Pharm. Sci., 1970, 59, 688-691

30 H.G. Kristensen, P. Holm, and T. Schaefer, Powder Technol., $1985,44,227-237$

31 D.P. Rooke and J. Tweed, Int. J. Eng. Sci., 1973, 11, 285-290

32 H. Awaji and S. Sato, J. Eng. Mater. Technol., 1978, 100, 175182

33 C. Atkinson, R.E. Smelser, and J. Sanchez, Int. J. Fract., 1982, 18, 279-291

34 D.K. Shetty, A.R. Rosenfield, and W.H. Duckworth, J. Am. Ceram. Soc., 1985, 68, C-325

35 D.K. Shetty, A.R. Rosenfield, and W.H. Duckworth, J. Am. Ceram. Soc., 1986, 69, 437-443

36 D. Singh and D.K. Shetty, J. Am. Ceram. Soc., 1989, 72, 78-84

37 J.K. Clobes and D.J. Green, J. Mater. Sci., 2002, 37, 2427-2434
38 R.J. Fowell and C. Xu, Int. J. Rock Mech. Min. Sci. Geomech. Abstr., 1994, 31, 571-579

39 G.R. Krishnan, X.L. Zhao, M. Zaman, and J.-C. Roegiers, Int. J. Rock Mech. Min. Sci., 1998, 35, 695-710

40 Z. Zhang and D.J. Green, J. Am. Ceram. Soc., 2002, 85, 13301332

41 M. Uppalapati and D.J. Green, J. Am. Ceram. Soc., 2005, 88, 1397-1402

42 R.J. Hunter, Foundations of Colloid Science, Oxford University Press, Oxford ; New York, 2nd ed, 2001

43 J.A. Lewis, J. Am. Ceram. Soc., 2000, 83, 2341-2359

44 G.V. Franks and F.F. Lange, Colloids Surf. Physicochem. Eng. Asp., 1999, 146, 5-17

45 G.V. Franks and F.F. Lange, J. Eur. Ceram. Soc., 2001, 21, 893899

46 K. Prabhakaran, S.P. Tambe, A. Melkeri, N.M. Gokhale, and S.C. Sharma, J. Am. Ceram. Soc., 2008, 91, 3608-3612

47 S.J. Wheeler and V. Sivakumar, Géotechnique, 1995, 45, 35-53

48 Y.J. Cui and P. Delage, Géotechnique, 1996, 46, 291-311

49 S. Kitsunezaki, J. Phys. Soc. Jpn., 2010, 79, 124802

50 S. Kitsunezaki, Adv. Powder Technol., 2011, 22, 311-318

51 A. Sarkar and M.S. Tirumkudulu, Soft Matter, 2012, 8, 303-306

52 L. Goehring, W.J. Clegg, and A.F. Routh, Phys. Rev. Lett., 2013, 110, 024301

53 R. Sengupta and M.S. Tirumkudulu, Soft Matter, 2016, 12, 3149-3155

54 N. Birk-Braun, K. Yunus, E.J. Rees, W. Schabel, and A.F. Routh, Phys. Rev. E, 2017, 95

55 G.V. Franks and F.F. Lange, J. Am. Ceram. Soc., 1996, 79, 31613168

56 J.L. Amorós, V. Cantavella, J.C. Jarque, and C. Felíu, J. Eur. Ceram. Soc., 2008, 28, 2823-2834

57 A. Schmeink, L. Goehring, and A. Hemmerle, Soft Matter, 2017, 13, 1040-1047

58 B.D. Johnson, M.A. Barry, B.P. Boudreau, P.A. Jumars, and K.M. Dorgan, Geo-Mar. Lett., 2012, 32, 39-48

59 M.J. Adams, D. Williams, and J.G. Williams, J. Mater. Sci., 1989, 24, 1772-1776

60 C. Chuanuwatanakul, C. Tallon, D.E. Dunstan, and G.V. Franks, Soft Matter, 2011, 7, 11464-11474

61 C. Kohlhauser, C. Hellmich, C. Vitale-Brovarone, A.R. Boccaccini, A. Rota, and J. Eberhardsteiner, Strain, 2009, 45, 34-44

62 J.S. Reed, Principles of Ceramics Processing, Wiley, New York, 2nd ed, 1995

63 G. Harrison, G.V. Franks, V. Tirtaatmadja, and D.V. Boger, KoreaAust. Rheol. J., 1999, 11, 197-218

64 D.A.R. Jones, B. Leary, and D.V. Boger, J. Colloid Interface Sci., 1991, 147, 479-495

65 D.A.R. Jones, B. Leary, and D.V. Boger, J. Colloid Interface Sci., 1992, 150, 84-96

66 R. Buscall, J.W. Goodwin, M.W. Hawkins, and R.H. Ottewill, J. Chem. Soc. Faraday Trans. 1 Phys. Chem. Condens. Phases, $1982,78,2873-2887$

67 G.M. Channell and C.F. Zukoski, AlChE J., 1997, 43, 1700-1708

68 H.R. Hertz, J. Für Reine Angew. Math., 1882, 156-171

69 B.W. Darvell, J. Mater. Sci., 1990, 25, 757-780

70 G. Hondros, Aust. J. Appl. Sci., 1959, 10, 243-268

71 S.P. Timothy, J.M. Pearson, and I.M. Hutchings, Int. J. Mech. Sci., 1987, 29, 713-719

72 S.Y. Yarema, G.S. Ivanitskaya, A.L. Maistrenko, and A.I. Zboromirskii, Strength Mater., 1984, 16, 1121-1128

73 S. Herminghaus, Adv. Phys., 2005, 54, 221-261 
74 K. Hapgood and M. Rhodes, in Introduction to Particle Technology, ed. M.J. Rhodes, John Wiley \& Sons, Ltd, 337-358, 2008

75 P. Jonsén and H.-Å. Häggblad, Int. J. Solids Struct., 2007, 44, 6398-6411

76 H. Guo, N.I. Aziz, and L.C. Schmidt, Eng. Geol., 1993, 33, 177188

77 B.C. Yu and F.F. Lange, J. Eur. Ceram. Soc., 2010, 30, 2795-2803

78 A. Mattern, R. Oberacker, and M.J. Hoffmann, Euro Ceramics VII, Trans Tech Publications, Zürich Switzerland, 2001

79 M.A. Mullier, J.P.K. Seville, and M.J. Adams, Powder Technol., 1991, 65, 321-333

80 G. Szendi-Horvath, Eng. Fract. Mech., 1980, 13, 955-961

81 G.R. Irwin, in Elasticity and Plasticity / Elastizität Und Plastizität, ed. S. Flügge, Springer Berlin Heidelberg, 551-590, 1958

82 S.B. Johnson, G.V. Franks, P.J. Scales, D.V. Boger, and T.W. Healy, Int. J. Miner. Process., 2000, 58, 267-304

83 C. Grein, H.-H. Kausch, and P. Béguelin, Polym. Test., 2003, 22, 733-746

84 P.L. Fernando and J.G. Williams, Polym. Eng. Sci., 1980, 20, 215220

85 J.M. Hodgkinson, A. Savadori, and J.G. Williams, J. Mater. Sci., 1983, 18, 2319-2336

86 R.T. Quazi, S.N. Bhattacharya, and E. Kosior, J. Mater. Sci., 1999, 34, 607-614

87 M.F. Ashby and D.R.H. Jones, Engineering Materials 1: An Introduction to Properties, Applications, and Design, Butterworth-Heinemann, Amsterdam ; Boston, 4th ed, 2012

88 K. Kendall, N.M. Alford, and J.D. Birchall, Proc. R. Soc. Lond. Ser. Math. Phys. Sci., 1987, 412, 269-283

89 D. Goertz and R. Knight, GEOPHYSICS, 1997, 63, 171-183

90 M.A. Biot, J. Appl. Phys., 1962, 33, 1482-1498

91 G. Irwin, J. Appl. Mech., 1957, 24, 361-364

92 A.A. Griffith, Philos. Trans. R. Soc. Math. Phys. Eng. Sci., 1921, 221, 163-198

93 J.A. Coppola and R.C. Bradt, J. Am. Ceram. Soc., 1972, 55, 455460

94 J.-F. Yang, T. Ohji, S. Kanzaki, A. Díaz, and S. Hampshire, J. Am. Ceram. Soc., 2002, 85, 1512-1516

95 D.P.H. Hasselman, J.A. Coppola, D.A. Krohn, and R.C. Bradt, Mater. Res. Bull., 1972, 7, 769-772

96 D.C.C. Lam, F.F. Lange, and A.G. Evans, J. Am. Ceram. Soc., 1994, 77, 2113-2117

97 G.R. Irwin, in Fracturing of Metal, ed. F. Joanssen, W.P. Roop, and R.T. Bayless, American Society for Metals, Cleveland OH, 174-166, 1948

98 E. Orowan, Rep. Prog. Phys., 1949, 12, 185

99 J.W. Hutchinson, A Course on Nonlinear Fracture Mechanics, Department of Solid Mechanics, Technical University of Denmark, Denmark, 1979 